\title{
Abraham Flexner and Robbert Dijkgraaf (2017) The Usefulness of Useless Knowledge. Princeton University Press: Princeton, New Jersey. 104 pages. ISBN: 9780691174761
}

\author{
Eric Livingston \\ elivings@une.edu.au
}

The Institute for Advanced Study is one of the most prestigious, exclusive research centers in the world, at least in pure mathematics and mathematical, theoretical physics. It was catapulted into world recognition in 1933 with the hiring of Einstein as one of its first professors. The faculty hold lifetime positions, have no teaching or publication requirements, and few committee obligations. The Institute currently supports some 200 visiting 'Members' and 'Visitors' each year, among whom are some of the world's most promising postdoctoral students. It is a private institute, it gives no degrees, and is supported by endowments, grants, and gifts, and, to some extent, by the U.S. National Science Foundation.[1]

The Usefulness of Useless Knowledge is, in turn, a small, short book (c. $18.4 \times 11.7 \times 1.4 \mathrm{~cm}, 104$ pages). It consists of two essays, one by Abraham Flexner, the other by Robbert Dijkgraad. Flexner was the first director of the Institute between 1930 and 1939; his essay was originally published in 1939 and lends its title to the book. Dijkgraad's essay, described as a 'companion essay', is the lead article. Dijkgraaf is a mathematical physicist, a professor at the Institute and its director since 2012.

Flexner's essay advances a menagerie of propositions, accompanied by a number of vignettes of various scientists. Flexner has a heroic appreciation of science: great scientists are typically individuals working alone. They are driven by unquenchable curiosity, apparently have no pecuniary interests, and pursue 'useless' knowledge whose value to society might lie in the distant future. For Flexner, technology and technological innovation have minor roles in scientific development; he is interested in thinking machines - brainiacs - even though some of his vignettes involve experimentalists. The less responsibilities these geniuses have, the more productive they will be. The fact that they are all together at the Institute - including faculty engaged in studies in economics, archeology, and the humanities - should increase their productivity as if they were tributaries joining together to form the mighty Mississippi.

Flexner's vignette about Nobel Laureate Paul Ehrlich (1854 - 1915) reflects some of the contradictions in the essay. Ehrlich's supervisor at the University of Strasbourg watched while Ehrlich was engaged in microscopic studies of animal tissue. Ehrlich was covering his desk with colored spots of different shapes and sizes. Ask what he was doing, Ehrlich said "Ich probiere" (something like "I'm giving it a go") whereupon the supervisor recognized Ehrlich's genius. According to Flexner, the supervisor "wisely left him alone". Next, we are told Ehrlich got his medical degree because his instructors realized that he would never be a practicing physician.

The idea seems to be that Ehrlich's achievements could be foretold: this is just the type of young genius that Flexner, seeking faculty for his 
new institute, would be looking to hire. Instead, Flexner was hiring Einstein, poaching faculty from Princeton University, and bringing in Nobel Laureates as visiting Members.

Flexner ends his essay thusly:

We make ourselves no promises, but we cherish the hope that the unobstructed pursuit of useless knowledge will prove to have consequences in the future as in the past. Not for a moment, however, do we defend the Institute on that ground. It exists as a paradise for scholars who, like poets and musicians, have won the right to do as they please and who accomplish most when enabled to do so. (p. $86-87$ )

Many of us, still waiting for TED talk invitations, may be misled by the celebration of our pursuit of useless knowledge. The Institute isn't hiring people because they have lots of curiosity, they're 'geniuses', and they promise to produce lots of useless knowledge. Flexner is dealing with thoroughbreds, winners of the Triple Crown. In his essay, Flexner is arguing for something, but what it is isn't immediately apparent.

Dijkgraad's essay "The World of Tomorrow" takes its name from the 1939 New York World's Fair but refers as well to the promise of the Institute. It begins, in part, by trying to clarify the meaning of 'useless knowledge'. At least since the turn of the 20th century, academic knowledge is disciplinary knowledge. The mathematicians and physicists at the Institute are among the creators of contemporary mathematics and theoretical physics. Their knowledge isn't useless, impractical, or knowledge 'not-yet-applied', at least for mathematicians and theoretical physicists; we just don't understand what they're talking about. As will be clarified shortly, Dijkgraad seems to end up with the practical distinction between, but no definitions of pure and applied research.

The second of Dijkgraad's philosophical 'moves' is to implicitly divorce himself from his faculty in 'historical studies' and the 'social sciences'. Flexner at the end of his essay briefly mentions Institute faculty in these fields and, among them, a female professor, Hetty Goldman. Dijkgraad doesn't seem to want any of this. He forgets everybody at the Institute except those in the discovering sciences, to all appearances excluding mathematicians as well except as they may aid and abet the theoretical physicists. The most likely reason is that it's difficult to compare achievements in sociology, art history, or economics with vaccines for rabies and anthrax, and the invention of the atomic bomb and the digital computer. If you want to celebrate research achievements, the case for the discovering sciences seems clearer, more powerful, and needs a lot less words.

A somewhat humorous element of the opening pages is that Dijkgraad discusses whether von Neumann may have been a greater genius than Einstein. The aim it seems is to show the power of the Institute's faculty - not even Einstein is the greatest of their geniuses - but one wonders whether Dijkgraad and other faculty keep genius tables in their offices.

Dijkgraad briefly says something about Flexner's life and philosophy. He then discusses the properties and benefits of 'blue-sky' research with examples such as the discovery of superconductivity in 1911 and the related discovery of the Higgs boson in 2012, the development of the internet, and the three-dimensional visualization of molecules by van't Hoff. None of the examples, however, seem directly related to the Institute. Then, starting on page 33, we get to the central point of the essay.

Dijkgraad tells us that U.S. government funding of research has been steadily declining, from $2.1 \%$ of the gross domestic product in 1964 to $0.8 \%$ at present, that "success rates in grant applications for basic research are plummeting across all disciplines", and that "[t]he 'metrics' used to assess the quality and impact of research proposals... systematically undercut pathbreaking scholarship in favor of more predictable goal-directed research." (p. 33 - 36) It doesn't take an Institute genius to figure out that Dijkgraad isn't talking about my pure, blue-sky research. He's talking about himself and the Institute (or at least part of the Institute). And, apparently, this is for our own good: with all the future consequences that could develop, Dijkgraad might as well say he wants more money for the good of our children. We might assume that this was the aim of Flexner's essay as well. Still during the Great Depression, Flexner was looking for benefactors that would 
help finance and grow the Institute for Advanced Study.

This somewhat cloaked pleading for money gives an ironic twist to the philosophical dream that Flexner and Dijkgraad espouse. The faculty at the Institute are the privileged ultra-elite of the academic world; their sheltered pursuit of discipli- nary knowledge is celebrated as their work's most attractive, promising feature. Yet, at the same time, in the same way, the Institute for Advanced Study seems a monument to a dying academic world. The Usefulness of Useless Knowledge presents an antiquated philosophy for a culture whose time may have already past.

\section{Notes}

1 Information on the finances of the Institute, including faculty salaries, have been difficult to find. I have relied here on Wikipedia, The Free Encyclopedia, "The Institute for Advanced Study", available at: https:// en.wikipedia.org/w/index.php?title=Institute_for_Advanced_Study\&oldid=819759705 (accessed 11 November 2017). The article indicates that the endowment in 2014 was $\$ 741$ million USD. 